\title{
抚仙湖现代湖泊沉积物中海绿石的发现 及成因的初步研究
}

\author{
王云飞 \\ （中国科学院南京地理研究所）
}

海绿石是传统的指示海相地层的标志矿物. 国内外学者认为它形成于特殊的海洋环境， 并以此判断和区分海相地层 ${ }^{\text {(1) }}$ 然而国外也报道过在非海相地层中发现海绿石, 但究其成因 不明,故末引起人们的注意.

1979 年以来, 我们对云南省抚仙湖进行 了综合研究和系统取样. 经分析, 发现海绿 石在湖泊沉积物中分布较广、含量较高. 抚 仙湖现代沉积物中海绿石的发现 (图 1)，对 深人认识海绿石的形成机制和沉积环境，具 有一定的理论和实际意义.

图 1 托仙湖海绿石 $(\times 96)$

\section{一、抚仙湖海绿石分布和矿物学特征}

海绿石在抚仙湖现代沉积物中, 分布在 水深 35-150米的湖底表层. 在 38 个矿物样品中有 28 个含海绿石, 含量占碎屑矿物总量的 0.8-14.5\%，平均含量为 $2.51 \%$ (图 2). 含海绿石的湖泊沉积物类型, 是具有一定分选的暗棕 色泥质粉细砂层. 无其在湖泊浊流沉积区 ${ }^{[2]}$, 这里湖底平坦、沉积速率甚缓，海绿石富集、含量 也较高. 底质中有少数点位不含海绿石,是由于这些地区的沉积环境或沉积物类型,对海绿石 形成不利.

抚仙湖的海绿石，颜色以墨绿色为主、黄绿色、绿黑色次之. 比重 2.65-2.70. 矿物折光 率变化较大,其中墨绿色的海绿石为 1.617. 其表面经扫描电镜放大,为细小层状晶体,与云母 类矿物结构较相似，但排列混乱、层间布有不规则的空隍(图 3).

海绿石的差热曲线,在 $100^{\circ} \mathrm{C} 、 450^{\circ} \mathrm{C}$ 和 $650^{\circ} \mathrm{C}$ 处有吸热反应（图 4), 各吸热谷的温度偏 低, 与现代海洋海绿石的曲线形态较相似 [3]. 经 X射线粉晶照相分析 (表 1), 它具有 $9.919 \AA$ 、 $4.50 \AA 、 2.60 \AA$ 等特征谱线,证实该矿物为海绿石, 但 $\mathrm{hkl}$ 反射中缺失一些晶面反射, 001 等 基面衍射曲线宽化、弥散显著, 矿物无序度明显, 与现代海洋海绿石结构相似 ${ }^{[3]}$. 化学成份经 电子探针分析(表 2)，含铁高而含铝低,也与现代海洋海绿石化学组成的特征一致 ${ }^{[3,5]}$.

由此可见,抚仙湖现代沉积物中的海绿石具有形成初期的矿物学特征. 
表 1 海绿石的 $\mathrm{X}$ 射线粉晶照相数据

\begin{tabular}{|c|c|c|c|c|c|c|}
\hline 样 品 昂 & \multicolumn{2}{|c|}{ 标准海绿石 4 (4) } & \multicolumn{2}{|c|}{ 抚仙湖海绿石 } & \multicolumn{2}{|c|}{ 抚仙湖盆地陆海绿石 } \\
\hline$h k l$ & $\boldsymbol{I}$ & $d(X)$ & $t$ & $d(A)$ & $l$ & $d(\AA)$ \\
\hline 001 & 10 & 10.02 & $\hat{4}$ & 9.919 & 8 & 10.00 \\
\hline 002 & 3 & 4.98 & 2 & 4.95 & 3 & 4.98 \\
\hline 020 & 8 & 4.53 & 8 & 4.50 & 8 & 4.52 \\
\hline $1 \mathrm{II}$ & 2 & 4.38 & & & 2 & 4.35 \\
\hline 112 & 4 & 3.64 & $\hat{5}$ & 3.63 & 4 & 3.62 \\
\hline 003,022 & 6 & 3.34 & 5 & 3.35 & 6 & 3.31 \\
\hline 112 & 3 & 3.09 & 3 & 3.08 & 3 & 3.08 \\
\hline $11 \overline{3}$ & 2 & 2.86 & & & 2 & 2.85 \\
\hline 023 & 1 & 2.67 & & & 1 & 2.67 \\
\hline $130,200,131$ & in & 2.59 & $\widehat{10}$ & 2.60 & 10 & 2.59 \\
\hline 132,201 & 6 & 2.40 & 7 & 2.41 & 6 & 2.40 \\
\hline $040,22 \pi$ & 1 & 2.27 & & & 2 & 2.27 \\
\hline \multirow[t]{3}{*}{133,202} & 2 & 2.16 & 2 & 2.159 & 1 & 2.15 \\
\hline & & & & & 2 & 2.08 \\
\hline & 2 & 2.02 & 2 & 2.02 & 1 & 2.03 \\
\hline 005 & 2 & 1.99 & 2 & 1.99 & 1 & 1.99 \\
\hline 224 & 1 & 1.815 & 1 & 1.815 & & \\
\hline $31 T, 24 T$ & 1 & 1.715 & & & 1 & 1.715 \\
\hline 240,310 & 3 & $1.66 i$ & 1 & 1.655 & 4 & 1.66 \\
\hline $060,33 I$ & 8 & 1.515 & 6 & 1.510 & 8 & 1.515 \\
\hline 260,400 & 3 & 1.310 & 2 & 1.311 & 4 & 1.310 \\
\hline \multirow[t]{2}{*}{170,350} & 1 & 1.252 & & & 2 & 1.253 \\
\hline & 1 & 1.204 & & & 1 & 1.204 \\
\hline
\end{tabular}

实验条件: 铁物辐射, 电区 40 千伏、电流 1.5 旁安、曝光时间 3.5 小时。

“へ”：线条宽化、弥散.

表 2 海绿石化学组成

\begin{tabular}{|c|c|c|c|c|c|c|c|c|c|c|}
\hline 样点 组成\% & $\mathrm{SiO}_{2}$ & $\mathrm{TiO}_{\mathbf{z}}$ & $\mathrm{Al}_{2} \mathrm{O}_{3}$ & $\mathrm{FeO}+\mathrm{Fe}_{2} \mathrm{O}_{3}$ & $\mathrm{CaO}$ & $\mathrm{MgO}$ & $\mathrm{K}_{2} \mathrm{O}$ & $\mathrm{Na}_{2} \mathrm{O}$ & $\mathrm{MnO}$ & 总计 \\
\hline 1.沅仙湖 18 & 52.68 & 0.03 & 5.17 & 18.38 & 0.22 & 5.94 & 10.41 & 0.04 & 0.08 & 92.95 \\
\hline 2.姃仙湖 37 & 53.61 & 0.02 & 3.62 & 20.79 & 0.22 & 6.79 & 10.49 & 0.02 & 0.09 & 95.65 \\
\hline 3.解海 No. $7^{(9)}$ & 51.63 & 0.12 & 7.63 & 25.41 & 1.15 & 8.05 & 4.55 & 0.26 & 0.20 & 99.00 \\
\hline 4. 蛔南-台淳浅海 & 44.20 & 0.16 & 5.08 & $1.16 \quad 23.91$ & 2.43 & 5.84 & 3.28 & 0.43 & 0.07 & 86.56 \\
\hline 5.抚仙湖盆地陆源海绿石 & 48.59 & 0.36 & 17.12 & 4.97 & 0.33 & 6.70 & 7.53 & 0.18 & 0.01 & 85.79 \\
\hline
\end{tabular}

样品 $1,2 、 3$ 为电子探针分析, 4,5 为化学分析. 


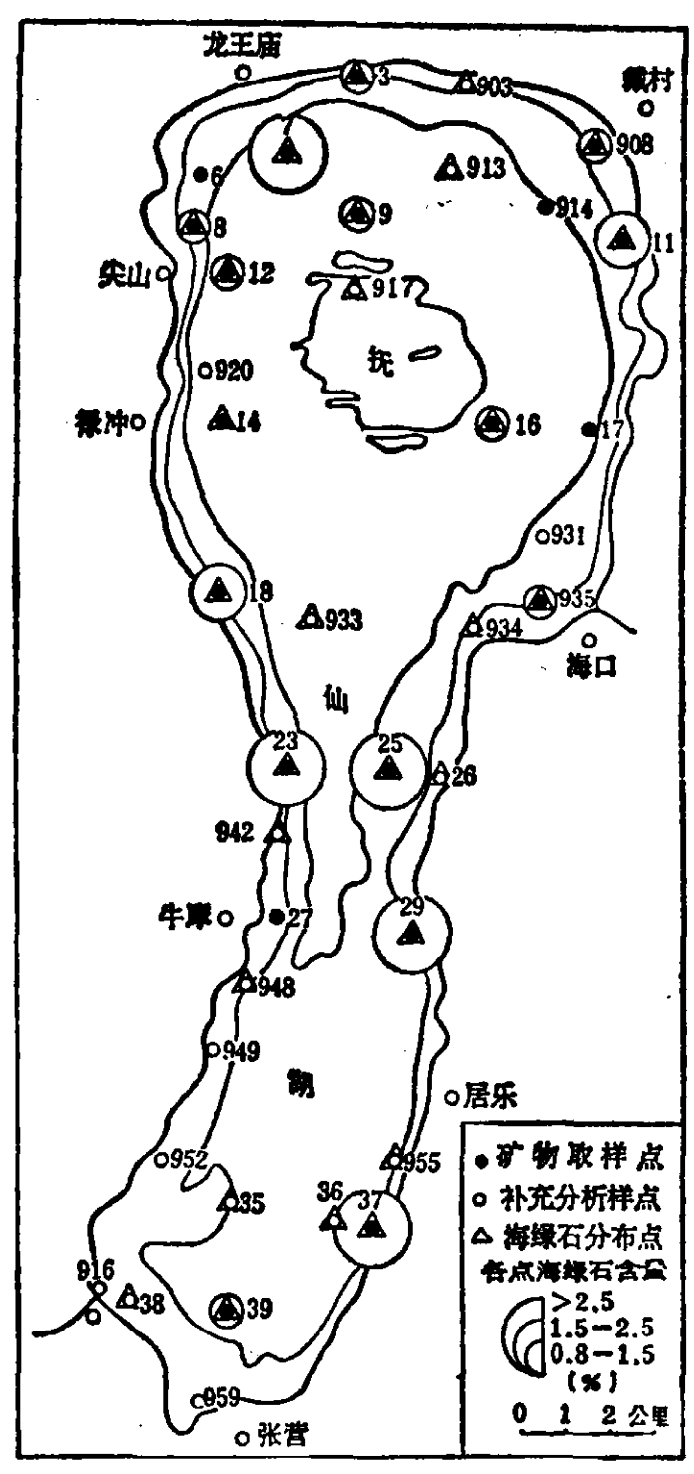

图 2 抚仙湖海绿石分布图

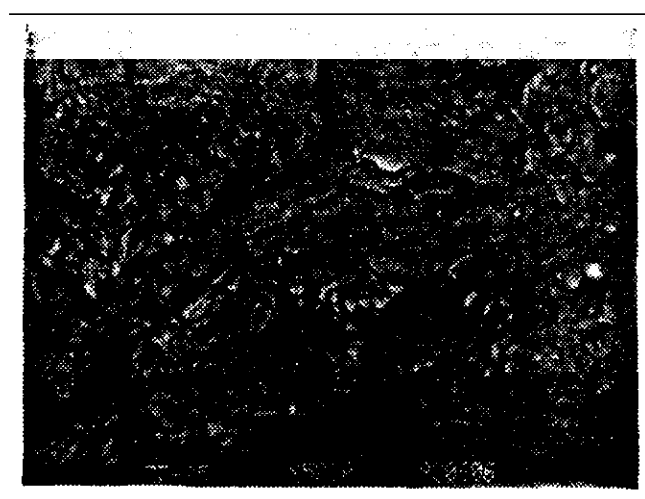

图 3 海绿石表面形貌 $(\times 4000)$

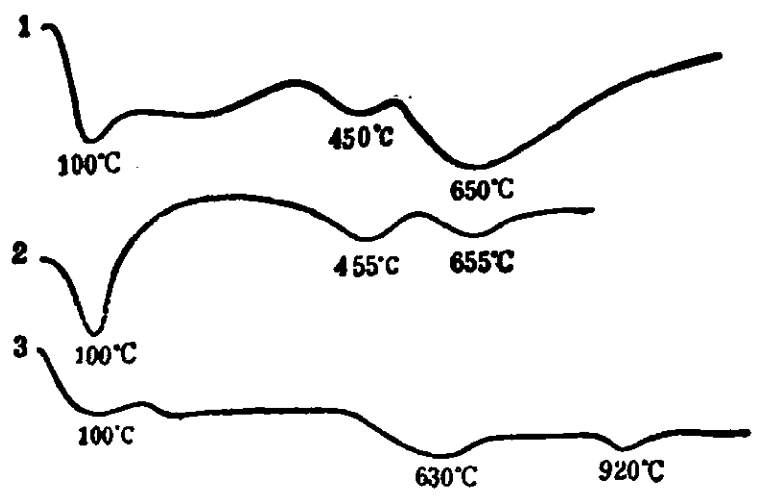

图 4 海绿石的差热曲线图 1. 抚仙湖现代沉积物中海绿石；2. 闽南一台游浅社 现代海洋海缘石; 3. 抚仙湖盆地东北部陆湶海绿石

\section{二、同陆源海绿石比较}

为了探讨湖泊海绿石成因, 这里分析一下陆源海绿石对现代湖泊沉积的影响程度. 据云 南省地质局调查和盆地四周 100 多个自然重砂分析资料*. 在盆地东北部山区, 寒武系底部 有一滺层含海绿石砂岩. 由于海绿石的不稳定性、经风化和投运绝大部分已经样化破坏 ${ }^{[1]}$. 陆 源海绿石对湖泊东北部现代沉积影响,经各河口自然重砂检测，含量均低于 $0.02 \%$. 可见陆源 海绿石仅响湖泊局部地区,其程度也很微弱.

此外，陆源海绿石不仅物理性质与湖泊海绿石不同，其晶体结构和化学组成也有明显区 别. 表 1 、2 和图 4 均列示了盆地东北部陆源海绿石的分析资料. 从中可看出: 其晶面反射完 整, 谱线清晰; 差热曲线中吸热反应温度值高; 化学组成属高铝低铁海绿石类型. 上述特征均 为古代地层中的海绿石所具有的共同特征 ${ }^{[4,5]}$. 上述资料再次证明，抚仙湖海绿石基本不是陆

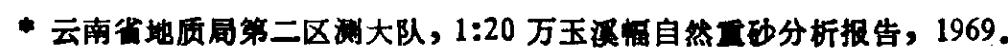


源再搬运而来的. 它只能是湖体本身地球化学过程的产物.

\section{三、沉积环境的主要特征}

抚仙湖是一个地堑式深水湖盆, 平均深度 89 米,最大水深 155 米. 湖滨陡蛸,陆源碎㞕沉 积物环湖成带状分布. 但该湖有湖泊浊流发育, 故在湖心深水区有薄层浊积物, 它们为海绿石 形成提供了有利的底质条件。

湖泊水位稳定, 湖底压力条件和热力学状况与海底很相似. 表层湖水平均温度 $18.3^{\circ} \mathrm{C}$, 随 深度增加, 水温年变幅减小,压力增大. 在水深 30 米处, 全年温度 $13.7^{\circ}-17^{\circ} \mathrm{C}$, 压力近 4 个 大气压,水深大于 100 米,常年水温保持 $13^{\circ} \mathrm{C}$ 左右, 压力超过 10 个大气压. 这些稳定的温度 场和较高压力条件,可能是海绿石形成的一个重要因素.

湖水属重碳酸镁 I 型, 平均矿化度 240 毫克/升. 底层水 $\mathrm{pH}$ 值 8一8.5, 沉积物表层 $\mathrm{Eh}$ 值 100 至负 50 毫伏. 而海绿石在碱性条件下稳定,成分中含有三价铁和二价铁离子的层状硅 酸盐矿物,因此湖底水化环境同样有利于海绿石形成.

上述环境特征与国内外报道的海绿石形成条件较相似,因此，该湖具备了海绿石形成的基 本条件。

\section{四、海绿石成因的初步分析}

根据显微镜和扫描电镜观察, 结合能谱仪测定成分, 湖泊海绿石成因主要有两种.

1. 长石、云母类矿物蚀变形成海绿石 ${ }^{[6]}$ 这类海绿石在形态上常保留长石和云母的部 分特征. 图 5 是正在蚀变中的正长石,上部和右下方已经变为绿色海绿石,其余部分保留着肉 红色正长石. 图 6 为褐红色黑云母, 边缘正发生海绿石化作用. 矿物蚀变初期, 其晶型转变为 海绿石所具有的镂片状晶型集合体，同时矿物与溶质不断进行离子交换,铁、铸、镁等离子逐步 进人层状晶格中, 原矿物部分元素流失, 矿物性质随之改变,最后成为半透明悬绿色海绿石.

2. 溶液凝聚形成的自生海绿石 ${ }^{[7]}$ 这类海绿石是在生物的有机地球化学作用参与下， 以 0.01 亳米碎屑为核心,在沉积界面缓慢凝聚形成(图 7). 在形成初期溶液聚沉淀,建立硅 氧四面体为主的层状晶体构造，并有规则的放射状增大，此时繁体无色透明. 以后铁、铎、镜 等组成海绿石的化学元素才进入层状晶格,逐步形成典型的海绿石矿物.

上述两种形成方式,均发生在有利于海绿石形成的湖底,目前这种形成过程还在进行中.

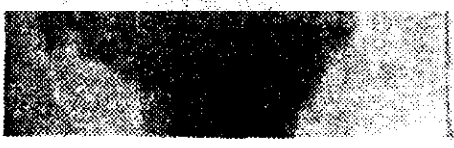

图 5 正长石的蚀变作用 $(\times 280)$

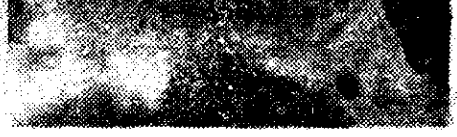

图 6 黑云母的蚀变作用 $(\times 280)$

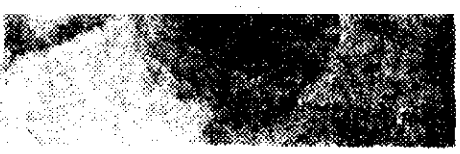

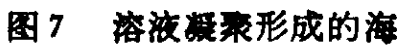
绿石 $(\times 280)$

五、结语

过去国内外学者较普遍认为, 海绿石只形成于海洋中, 并作为古代海相地层的指相矿物。 
骨来这种认识有待商榷. 因为在抚仙湖现代湖泊沉积物中发现了自生的海绿石, 而且明显犁 出它目前还在形成中, 表明海绿石能够在某些深水湖泊中形成. 因此在沉积相研究中, 有必要 对海绿石在指示沉积环境上的意义作深入探讨.

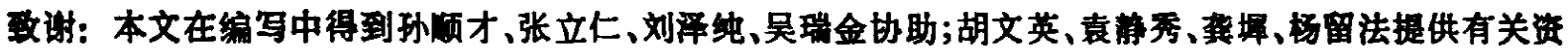
料;吕红味清绘附图。扫描电镜、能谱、差热分析由地质部无锡石油地质中心实验室协助完成; $\mathrm{x}$ 射线分析由 地质部南京地质矿产研究所协助完成;电子探针由冶金部桂林冶金地质研究所完成。在此一并致谢。

\section{- $\Rightarrow$ 文}

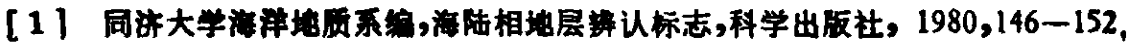

[2] 孙而才、张立仁,科学遗报,28(1981),11:678-681。

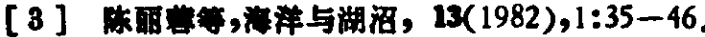

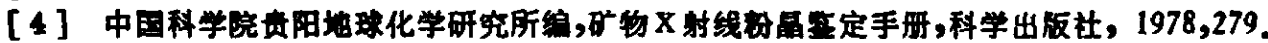

[5] 张乃缴,地质科学, $1981,4: 376-383$.

[6] Bireh, G. F., Willis, J. P. \& Riekard, R. S., Mar. Geol., 22(1976), 4: 271-283.

[7] Burst, J. F., Bull. Am. Assoc. Petrol. Gool, 12 (1858), 2: 310-327. 